\title{
New approaches and potential treatments for dry age-related macular degeneration
}

\author{
Novas abordagens e tratamentos potenciais da forma seca da degeneração macular relacionada à idade
}

\author{
Francisco Max Damico ${ }^{1}$, Fabio Gasparin ${ }^{2}$, Mariana Ramos Scolari ${ }^{3}$, Lycia Sampaio Pedral ${ }^{4}$, Beatriz Sayuri Takahashi ${ }^{2}$
}

\begin{abstract}
Emerging treatments for dry age-related macular degeneration (AMD) and geographic atrophy focus on two strategies that target components involved in physiopathological pathways: prevention of photoreceptors and retinal pigment epithelium loss (neuroprotection induction, oxidative damage prevention, and visual cycle modification) and suppression of inflammation. Neuroprotective drugs, such as ciliary neurotrophic factor, brimonidine tartrate, tandospirone, and anti-amyloid $\beta$ antibodies, aim to prevent apoptosis of retinal cells. Oxidative stress and depletion of essential micronutrients are targeted by the Age-Related Eye Disease Study (AREDS) formulation. Visual cycle modulators reduce the activity of the photoreceptors and retinal accumulation of toxic fluorophores and lipofuscin. Eyes with dry age-related macular degeneration present chronic inflammation and potential treatments include corticosteroid and complement inhibition. We review the current concepts and rationale of dry age-related macular degeneration treatment that will most likely include a combination of drugs targeting different pathways involved in the development and progression of age-related macular degeneration.
\end{abstract}

Keywords: Macular degeneration/drug therapy; Retina; Retinal pigment epithelium; Inflammation; Complement activation

\begin{abstract}
RESUMO
Os novos tratamentos para a forma seca da degeneração macular relacionada à idade (DMRI) e da atrofia geográfica têm sido baseados em duas estratégias que abordam componentes envolvidos nos mecanismos fisiopatológicos da doença: prevenção da perda de fotorreceptores e células do epitélio pigmentado da retina (indução de neuroproteção, diminuição do dano oxidativo e modificação do ciclo visual) e supressão da inflamação. As drogas neuroprotetoras visam evitar a apoptose das células retinianas, como o fator neurotrófico ciliar, o tartarato de brimonidina, a tandosporina e anticorpos antiamiloide $\beta$. A redução do dano oxidativo e a complementação de micronutrientes essenciais são os objetivos da fórmula AREDS. Os modificadores do ciclo visual reduzem a atividade dos fotorreceptores e o acúmulo de fluoróforos tóxicos e lipofuscina na retina. Olhos com a forma seca da degeneração macular relacionada à idade apresentam inflamação crônica e os novos tratamentos incluem corticosteroides e inibidores do sistema complemento. Neste artigo, revisamos o estágio atual do tratamento da forma seca da degeneração macular relacionada à idade que provavelmente será feito através da combinação de drogas que agem em diferentes componentes envolvidos no aparecimento e na progressão da degeneração macular relacionada à idade.
\end{abstract}

Descritores:Degeneraçãomacular/quimioterapia; Retina; Epitélio pigmentado daretina; Inflamação; Ativação do complemento

\section{INTRODUCTION}

Age-related macular degeneration (AMD) is the leading cause of severe vision loss in people aged over 50 and its prevalence increases exponentially after the age of $70^{(1,2)}$. Although neovascular AMD is the most damaging form of the disease, dry AMD accounts for approximately $90 \%$ of all cases. Geographic atrophy (GA), the advanced nonneovascular form of AMD, accounts for $35 \%$ of all cases of late-stage $A M D$ and $20 \%$ of legal blindness attributable to $A M D^{(3)}$. Intravitreal injection of anti-vascular endothelial growth factor (VEGF) agents has revolutionized the treatment and prognosis of neovascular AMD. However, dry AMD treatment still remains a challenge. Currently, the only approved treatment for dry AMD is the use of Age-Related Eye Disease Study (AREDS)-based vitamin supplements, which does not halt the vision loss but lowers the risk of developing advanced stages of AMD (either geographic atrophy or neovascular AMD) and reduces visual loss in people at risk for the disease. In addition, the AREDS formula does not prevent GA from forming or progressing ${ }^{(4,5)}$.

Over the last years, a significant amount of research has been focusing on the physiopathology of dry AMD and new treatment approaches. However, research has been hampered by some issues, such as the multifactorial nature of dry AMD, its complex physiopathology, the lack of an animal model for dry AMD, and the lack of in vitro systems for testing new drugs.
In this article, we will review dry AMD emerging treatments that have basically focused on two strategies: prevention of photoreceptors and retinal pigment epithelium (RPE) cells loss, and suppression of inflammation. The former can be achieved by neuroprotection induction, oxidative damage prevention, and visual cycle modification (Table 1). Before getting into details on the drugs under research, the physiopathology of dry AMD will be presented.

\section{Dry AMD and GEOGRAPHIC ATROPHy PATHOGENESIS}

The processes involved in dry AMD and GA pathogenesis are not completely understood. Current investigations suggest that oxidation and inflammation play important roles in the pathogenesis of the diseases.

Docosahexaenoic acid (DHA) is an omega-3 fatty acid that is a primary structural component of the human retina, comprising $60 \%$ of the polyunsaturated fatty acids in the retina. It is the most oxidizable fatty acid in the body and is found in the membrane of the outer segment of the photoreceptors ${ }^{(6)}$. The human macula has a lifelong exposure to light and very high oxygen consumption. This microenvironment is highly permissive for the oxidative damage of reactive oxygen to DHA. DHA peroxidation generates lipofuscin, a yellow-brown pigment that represents undigested material from the oxidation of DHA. Lipofuscin cannot be degraded by the lysosomes 
Table 1. New drugs in the pipeline for the treatment of dry AMD and GA

\begin{tabular}{|c|c|c|}
\hline Drug and mechanism of action & Route of administration & Manufacturer \\
\hline \multicolumn{3}{|c|}{ Prevention of photoreceptors and retinal pigment epithelim (RPE) loss } \\
\hline \multicolumn{3}{|l|}{ Neuroprotection } \\
\hline Brimonidine tartrate & Intravitreal implant & Allergan, Inc. \\
\hline Tandospirone & Topical & Alcon Laboratories, Inc. \\
\hline \multicolumn{3}{|l|}{ Anti-amyloid $\beta$ antibody } \\
\hline RN6G & Intravenous & Pfizer, Inc. \\
\hline \multicolumn{3}{|l|}{ Oxidative damage prevention } \\
\hline AREDS formulation & & Bausch \& Lomb, Inc. \\
\hline \multicolumn{3}{|l|}{ Visual cycle modulators } \\
\hline Fenretinide & Oral & ReVision Therapeutics \\
\hline ACU-4429 & Oral & Acucela, Inc. \\
\hline \multicolumn{3}{|l|}{ Complement system inhibition } \\
\hline POT-4 & Intravitreal injection & Potentia Pharmaceuticals \\
\hline Eculizumab & Intravenous & Alexion Pharmaceuticals \\
\hline ARC1905 & Intravitreal injection & Ophthotech Corp. \\
\hline FCFD4514S & Intravitreal injection & Genentech, Inc. \\
\hline
\end{tabular}

in the retinal pigment epithelium (RPE) and accumulates within it, increasing RPE lysosomal pH. Continuous lipofuscin formation along with $\mathrm{pH}$ change interfere with proper lysosomal enzymes function and impair their phagosomal activity ${ }^{(7)}$. With time, RPE becomes overwhelmed with cellular debris and vitamin A metabolites, such as A2-E (a toxic vitamin A dimer). When present in excessive levels, lipofuscin and A2-E damage photoreceptors and choriocapillaris, leading to geographic atrophy ${ }^{(8)}$.

Besides being toxic to the RPE, A2-E has also been shown to activate the complement cascade ${ }^{(9,10)}$. Complement system is part of the immune system called the innate immune system. It consists of many small proteins in the blood and is a potent mechanism of host defense against pathogens and abnormal cells. Its activation leads to an inflammatory response, therefore it must be tightly regulated.

There are 3 pathways of complement activation (classical, lectin, and alternative pathways) that converge into a final common pathway, when a protein named factor C3 is generated. Ultimately, factor C3 cleavage results in formation of the membrane attack complex, the cytotoxic component of the complement system that causes cell lysis (Figure 1). Factor C3 plays an important role in an amplification loop of complement system activation.

Complement factor $\mathrm{H}(\mathrm{CFH})$ is a circulating protein that inhibits directly or indirectly the three complement activation pathways. It downregulates the system and prevents it from getting out of control. In patients with early and late AMD, many CFH polymorphisms have been described ${ }^{(11)}$. With abnormal $\mathrm{CFH}$, complement system downregulation is defective and excess inflammation may result. Additionally, histological analysis of drusen revealed the presence of complement factors and the terminal membrane attack complex ${ }^{(12)}$. It is still unknown whether those complement factors are systemically or locally produced in the retina ${ }^{(13)}$. Regardless of its origin, the retina with dry AMD presents with chronic subclinical local inflammation that may trigger and/or sustain the damaging process ${ }^{(14,15)}$.

Chronic local inflammation has also been found in other degenerative diseases characterized by accumulation of debris that can no longer be eliminated by the usual routes, such as atherosclerosis ${ }^{(16)}$ and Alzheimer disease ${ }^{(17)}$. Some components, like vitronectin and amyloid $\beta$, present in deposits found in those diseases, have also been shown in retinal drusen from eyes with $\mathrm{AMD}^{(12,18)}$. It is postulated that the presence of such debris triggers a local inflammatory response that can activate the immune system ${ }^{(19-22)}$. The inflammatory cells chronically present in that microenvironment release cytokines that attract more inflammatory cells. These cells extend their processes through the Bruch's membrane and basal lamina, making them thicken and creating a drusen inflammatory core. Over time, these changes may lead to impaired diffusion of waste products from hormones and nutrients to the RPE, including oxygen and vitamin $A^{(7,23)}$.

\section{TREATMENT APPROACHES FOR DRY AMD AND GEOGRAPHIC ATROPHY}

Although the complete pathological mechanisms underlying dry AMD have not been completely understood, new pharmacological treatments have emerged over the last years. Different approaches will be presented according to the different strategies and pharmacological targeting of components involved in dry AMD physiopathological pathways.

\section{Prevention of photoreceptors and RPE cells loss}

One of the focused strategies is the prevention of photoreceptors and RPE cells loss, which include neuroprotection induction, oxidative damage prevention, and visual cycle modification.

\subsection{Neuroprotection induction}

Neuroprotective drugs aim to preserve macular function by preventing apoptosis of viable RPE cells and photoreceptors. The main drugs under investigation will be described: Ciliary neurotrophic factor (CNTF), brimonidine tartrate, tandospirone, and anti-amyloid $\beta$ antibodies.

- Ciliary neurotrophic factor (CNTF) is a potent neurotrophic factor that slows down loss of photoreceptors in various animal models of retinal degeneration ${ }^{(24-27)}$, and there are evidences 


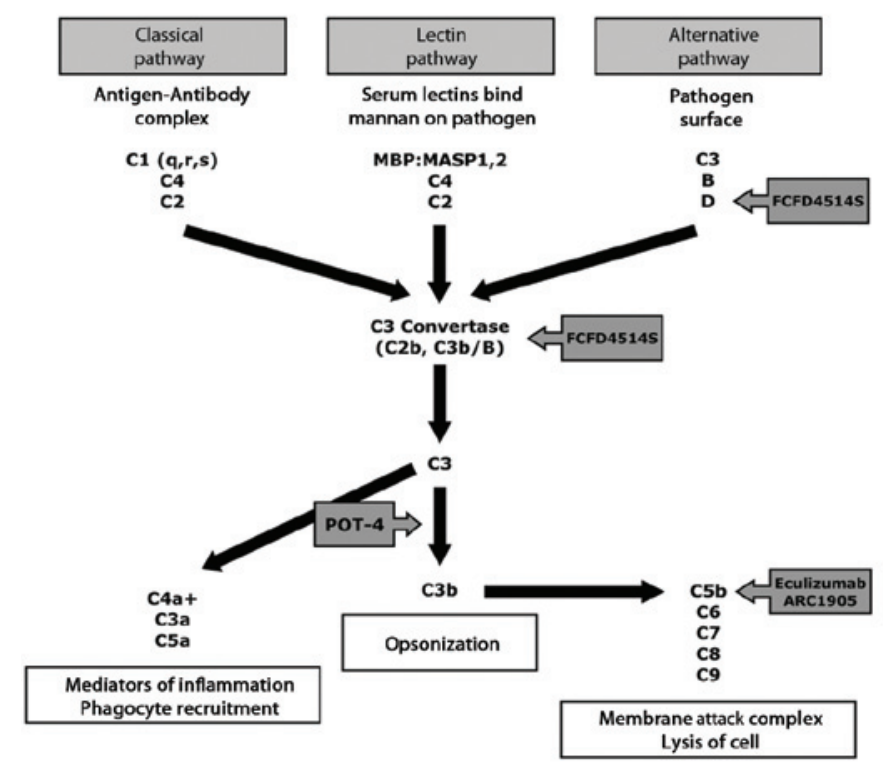

Figure 1. The three pathways of complement system activation (classical, lectin, and alternative pathways). In arrowed boxes are therapeutic agents currently investigated in clinical trials.

of its efficacy in human retinitis pigmentosa ${ }^{(28)}$. NT-501 (Neurotech Pharmaceuticals, USA) is an intravitreal sustained-release device made of a semipermeable polymer outer membrane which contains an internal yarn scaffold that supports live human cells (encapsulated cell technology, ECT). In this case, the cells are genetically engineered to produce human CNTF. ECT implants are distinct from other drug delivery implants in that they do not primarily store drug but rather produce the therapeutic drug to be delivered in situ. The implant is $6 \mathrm{~mm}$ long with $1 \mathrm{~mm}$ diameter, is inserted into the vitreous and releases CNTF in two different output rates for a year or longer: 5 and $20 \mathrm{ng} /$ day $^{(26,28,29)}$

NT-501 was evaluated in a phase 2 clinical trial that enrolled 51 patients with GA secondary to $\mathrm{AMD}^{(29)}$. Patients were randomized to 3 groups (low and high dose of CNTF, or sham injection) and were followed up for 1 year. At 12 months, patients who received the low- and high-dose implants presented a significant increase in retinal thickness that may reflect increased photoreceptors metabolic activity or an increased number of photoreceptors. CNTF appeared to preserve visual acuity and a mean 0.8-letter gain was present in the high-dose group vs a mean 9.7-letter loss in the combined low-dose and sham groups. However, CNTF had no apparent effect on the progression of GA. Interestingly, no visual acuity loss occurred in eyes with 20/63 or better baseline vision when treated with high-dose implants. A phase 3 study is planned.

- Brimonidine tartrate (Allergan Inc., USA) is an alpha-2 adrenergic receptor agonist. These receptors are present in the mammalian retina ${ }^{(30)}$ and brimonidine tartrate has been shown to protect retinal ganglion cells, bipolar cells, and photoreceptors in numerous models of experimental nerve injury, including retina ischemia, ocular hypertension, retinal phototoxicity, and partial optic nerve crush ${ }^{(31-33)}$. Brimonidine tartrate works as a neuroprotectant activating some pathways inside and outside cells, such as increasing the expression of basic fibroblast growth factor mRNA, a cytokine that delays apoptosis, increases the expression of proteins that regulate mitochondrial membrane permeability and inhibit apoptosis ${ }^{(34)}$, and suppresses the accumulation of glutamate that causes neuronal cell death ${ }^{(35)}$. Brimonidine tartrate is delivered by a sustainedrelease biodegradable implant that is injected into the vitreous through a 22-gauge needle with the same applicator system used to deliver dexamethasone (Ozurdex; Allergan Inc., USA).

A 2-year phase 2 clinical trial evaluating the brimonidine implant in patients with GA is under way. Patients were randomized to 3 treatment groups to receive the implant at 200 or $400 \mu \mathrm{g}$, or sham treatment (ClinicalTrials.gov number, NCT00658619). A second implant will be injected 6 months after the first one. Results of this study are still pending.

- Tandospirone (Alcon Laboratories Inc., USA) is a selective serotonin 1A agonist that is used as anxiolytic and antidepressant. In an animal model, it has been shown to protect photoreceptors and RPE cells from photo-oxidative stress by decreasing microglia activation/recruitment and complement deposition in the outer retinax ${ }^{(36)}$. A 1-year phase 2 clinical trial including patients with GA is ongoing and two doses of topical tandospirone are being tested (ClinicalTrials.gov number, NCT00890097).

- Anti-amyloid $\beta$ antibodies reduce the accumulation of amyloid $\beta$, a toxic byproduct which deposit is found in drusen and in patients with GA. Amyloid $\beta$ is believed to be an important component of local inflammatory reaction that may contribute to the etiology of dry AMD. Two drugs using this strategy are being tested: Glatiramer acetate and RN6G.

Glatiramer acetate (Copaxone; Teva Pharmaceutical, Israel) is an immunomodulatory drug currently used to treat multiple sclerosis. Its mechanism of action is not fully elucidated but there are evidences that it suppresses T-cells, downregulates inflammatory cytokines, reduces amyloid $\beta$-induced retinal microglial cytotoxicity, and allows a neuroprotective phenotype of microglia to form ${ }^{(37)}$. The analysis of the drusen in patients with Alzheimer disease treated with glatiramer acetate showed that the drug reduces drusen area(38). Specifically in patients with dry AMD, glatiramer acetate shrank or eliminate more drusen than did sham treatment ${ }^{(39)}$.

RN6G (Pfizer Inc., USA) is a humanized monoclonal antibody against amyloid $\beta$ that binds and sequesters amyloid $\beta$ in the retinal periphery, reducing the pool of toxic species available in the macula and preventing its accumulation. In a mouse model of AMD, RN6G is administered systemically and has been shown to reduce amyloid $\beta$ deposits in the retina. In addition, RN6G preserves animals retinal function and maintains normal RPE morphology ${ }^{(40)}$. Phase 1 clinical trial has been completed and a phase 2 study is planned, in which AMD patients will be treated monthly for 6 months.

\subsection{Oxidative damage prevention}

AMD is a multifactorial disease caused by genetic predisposition, lifelong exposure to free radicals, exposure to environmental toxins, and low levels of naturally occurring antioxidants. Oxidative stress and depletion of essential micronutrients are important factors for AMD progression. Indeed, the AREDS formula (Bausch \& Lomb Pharmaceuticals Inc., USA) is the first effective treatment to slow the progression of the disease for patients at high risk for developing advanced AMD.

AREDS is a multi-center, randomized clinical trial that included more than 3,000 patients over a 5-year period ${ }^{(4)}$. It was designed to evaluate the effect of high doses of antioxidants and zinc on the progression of AMD. High levels of antioxidants (vitamin C, vitamin $\mathrm{E}$, and beta-carotene) and zinc significantly reduced the risk of advanced AMD and associated vision loss. AREDS showed that people at high risk of developing advanced AMD lowered their risk by about $25 \%$ when treated with the micronutrients combination. In the same high-risk group, which included people with intermediate AMD or advanced AMD in one eye but not the other eye, the nutrients reduced the risk of vision loss by about 19\%. For patients who had either no AMD or early AMD, the nutrients did not provide an apparent benefit.

AREDS2 is a multicenter, randomized clinical trial designed to assess the effects of oral supplementation of macular xanthophylls 
(lutein and zeaxanthin) and/or long-chain omega-3 fatty acids (DHA and EPA - eicosapentaenoic acid) on the progression to advanced AMD. These micronutrients are believed to function as antioxidants, anti-inflammatory, and anti-angiogenic agents. An additional goal of the study is to assess whether forms of the AREDS nutritional supplement with reduced zinc and/or no beta-carotene works as well as the original supplement in reducing the risk of progression to advanced AMD. Enrollment was concluded in 2008 and participants are being followed for approximately 5 years (ClinicalTrials.gov number, NCT00345176).

\subsection{Visual cycle modification}

Visual cycle modulators are pharmacologic compounds intended to modulate the visual cycle in patients with AMD. Visual cycle modulators essentially "slow down"the activity of the photoreceptors and reduce the metabolic load on these cells. So, these compounds may slow the deterioration by reducing the accumulation of toxic fluorophores (mainly A2-E) and lipofuscin, thereby preventing the loss of photoreceptors and RPE cells. Two drugs are currently being tested: Fenretinide and ACU-4429.

- Fenretinide (ReVision Therapeutics, USA) is a synthetic derivative of vitamin $A$, which after oral intake, strongly competes with vitamin $A$ for binding to the retinol binding protein (RBP). The complex fenretinide-RBP is excreted in urine due to its relatively small size and decreases the available pool of vitamin A available for uptake at the RPE. Because A2-E biosynthesis relies ultimately on circulating vitamin $A$, in doing this, fenretinide inhibits the accumulation of A2-E and lipofuscin in cells of the $\mathrm{RPE}^{(41)}$. Fenretinide has been shown to have anti-angiogenic and anti-inflammatory properties ${ }^{(42)}$.

A multicenter, randomized phase 2 clinical trial included 246 patients with GA followed up for 1 year who were randomized to $100 \mathrm{mg}$, $300 \mathrm{mg}$ oral fenretinide, and placebo. This study showed reduction in lesion growth that correlated with reduction in $\mathrm{RBP}^{(43)}$. In addition, patients in both treatment arms presented reduced incidence of choroidal neovascularization ${ }^{(42)}$.

- ACU-4429 (Acucela, Inc., USA) is a small, non-retinoid molecule that modulates RPE65, an enzyme required to convert trans-retinol to cis-retinol within the RPE. It has been shown to prevent the accumulation of $\mathrm{A} 2-\mathrm{E}$ in the mouse retina, thereby slowing down the visual cycle. ACU-4429 is given orally and acts selectively on the rod photoreceptors, the major source of A2-E in the retina.

Phase 1 clinical trial showed a dose-dependent inhibition of the $b$ wave on electroretinogram. Adverse events, including dyschromatopsia and alteration in dark adaptation, were mild and transient ${ }^{(44)}$. A phase 2 clinical trial is enrolling patients with dry AMD and GA (Clinical Trials.gov number, NCT01002950). Patients will receive once-daily dosing over 3 months with 3 different doses of ACU-4429 or placebo.

\section{Suppression of inflammation}

There is a large amount of evidence that inflammation plays an important role in causing both advanced dry AMD with atrophy and choroidal neovascularization. Inflammatory elements are present in drusen, such as components of the complement system, acute-phase proteins, proteins that modulate the immune response, lipofuscin, and dendritic cells $s^{(12,14,45-50)}$. Therefore, it is likely that if inflammation could be reduced, progression of AMD could be slowed. This hypothesis is being investigated with a number of approaches, including corticosteroid treatment and complement inhibition.

\subsection{Corticosteroids}

Corticosteroids are a class of chemicals that are naturally produced in the adrenal cortex and analogues of these hormones, which are synthesized in laboratories. Corticosteroids are involved in a wide range of physiologic processes including the regulation of inflammation.
- Fluocinolone acetonide (Alimera Sciences, USA) is a potent corticosteroid that presented a neuroprotective effect in an animal model by dampening retinal neuroinflammation ${ }^{(51,52)}$. It is postulated that the sustained-release implant, which delivers fluocinolone acetonide directly into the vitreous, may suppress retinal neuroinflammation and slow the rate of retinal degeneration. The implant is inserted into the vitreous via a 25-gauge injector. A phase 2 clinical trial enrolling patients with GA is under way.

\subsection{Complement system inhibitors}

Several therapeutic agents involved in the complement cascade are under investigation.

- POT-4 (Potentia Pharmaceuticals, USA) is a synthetic peptide that reversibly binds complement factor C3 and inhibits activation of the complement cascade (Figure 1). POT-4 prevents cleavage of C3 into C3a and C3b, which eventually leads to the formation of the membrane attack complex. As C3 is a central component of all complement activation pathways, its inhibition shuts down all downstream complement activation that could otherwise lead to local inflammation, tissue damage, and up-regulation of angiogenic factors. POT-4 is injected directly into the vitreous and forms an intravitreal blob, which slowly releases the drug over time. Results of a phase 1 clinical trial indicate that POT-4 is safe even in high doses (ClinicalTrials. gov number, NCT00473928) and a phase 2 is being planned for the treatment of both dry and wet AMD to further define its efficacy profile.

- Eculizumab (Alexion Pharmaceuticals, USA) is a humanized IgG antibody that selectively inhibits the cleavage of $\mathrm{C} 5$ factor into $\mathrm{C} 5 \mathrm{a}$ and $\mathrm{C5b}$ (Figure 1). Because it is a C5 inhibitor, eculizumab inhibits further downstream on the complement cascade than C3 inhibitors, thereby reducing only terminal complement activity, so the proximal functions of complement system remains intact. A phase 2 study with patients with dry AMD is under way (ClinicalTrials.gov number, NCT00935883).

- ARC1905 (Ophthotech Corp., USA) is an aptamer that is a potent and selective inhibitor of factor C5 of the complement cascade (Figure 1). The rationale is the same than that of eculizumab and a phase 1 study is under way (ClinicalTrials.gov number, NCT 00950638).

- FCFD4514S (Genentech Inc., USA) is a human monoclonal antibody that inhibits complement factor $\mathrm{D}$, a protein involved in the alternative complement pathway (Figure 1). Phase 1 study is under way (ClinicalTrials.gov numbers, NCT 00973011 ).

\section{CONCLUSION}

Currently, the only approved treatment for dry AMD is the use of AREDS formulation. However, this multivitamin complex does not prevent AMD and its positive effects are modest as it only slows down the progression for patients at high risk for advanced AMD. Many advances in the fields of epidemiology, pathogenesis, and genetics have been produced in the last decade. Novel treatment strategies are under investigation for the treatment of dry AMD and GA, such as prevention of photoreceptors and RPE cells loss, and suppression of inflammation. In the near future, it is likely that the treatment of dry AMD will be a combination of different drugs that will target the different pathways involved in the development and progression of AMD.

\section{REFERENCES}

1. Ambati J, Ambati BK, Yoo SH, lanchulev S, Adamis AP. Age-related macular degeneration: etiology, pathogenesis, and therapeutic strategies. Surv Ophthalmol. 2003; 48(3):257-93.

2. van Leeuwen R, Klaver CC, Vingerling JR, Hofman A, de Jong PT. Epidemiology of age-related maculopathy: a review. Eur J Epidemiol. 2003;18(9):845-54. 
3. Klein R, Klein BE, Knudtson MD, Meuer SM, Swift M, Gangnon RE. Fifteen-year cumulative incidence of age-related macular degeneration: the Beaver Dam Eye Study. Ophthalmology. 2007;114(2):253-62.

4. Age-Related Eye Disease Study Research Group. A randomized, placebo-controlled clinical trial of high-dose supplementation with vitamins $C$ and $E$, beta carotene, and zinc for age-related macular degeneration and vision loss: AREDS report no 8. Arch Ophthalmol. 2001;119(10):1417-36. Erratum in: Arch Ophthalmol. 2008;126(9):1251.

5. Age-Related Eye Disease Study Research Group. A randomized, placebo-controlled, clinical trial of high-dose supplementation with vitamins $C$ and $E$ and beta carotene for age-related cataract and vision loss: AREDS report no 9. Arch Ophthalmol. 2001; 119(10):1439-52. Erratum in: Arch Ophthalmol. 2008;126(9):1251.

6. Fliesler SJ, Anderson RE. Chemistry and metabolism of lipids in the vertebrate retina. Prog Lipid Res. 1983;22(2):79-131.

7. Zarbin MA. Current concepts in the pathogenesis of age-related macular degeneration. Arch Ophthalmol. 2004;122(4):598-614.

8. Holz FG, Bellman C, Staudt S, Schütt F, Völcker HE. Fundus autofluorescence and development of geographic atrophy in age-related macular degeneration. Invest Ophthalmol Vis Sci. 2001:42(5):1051-6.

9. Zhou J, Jang YP, Kim SR, Sparrow JR. Complement activation by photooxidation products of $\mathrm{A} 2 \mathrm{E}$, a lipofuscin constituent of the retinal pigment epithelium. Proc Natl Acad Sci U S A. 2006;103(44):16182-7.

10. Radu RA, Hu J, Yuan Q, Welch DL, Makshanoff J, Lloyd M, et al. Complement system dysregulation and inflammation in the retinal pigment epithelium of a mouse model for Stargardt macular degeneration. J Biol Chem. 2011;286(21):18593-601.

11. Haddad S, Chen CA, Santangelo SL, Seddon JM. The genetics of age-related macular degeneration: a review of progress to date. Surv Ophthalmol. 2006;51(4):316-63.

12. Johnson LV, Ozaki S, Staples MK, Erickson PA, Anderson DH. A potential role for immune complex pathogenesis in drusen formation. Exp Eye Res. 2000;70(4):441-9.

13. Buschini E, Piras A, Nuzzi R, Vercelli A. Age related macular degeneration and drusen: neuroinflammation in the retina. Prog Neurobiol. 2011;95(1):14-25.

14. Hageman GS, Luthert PJ, Victor Chong NH, Johnson LV, Anderson DH, Mullins RF. An integrated hypothesis that considers drusen as biomarkers of immune-mediated processes at the RPE-Bruch's membrane interface in aging and age-related macular degeneration. Prog Retin Eye Res. 2001;20(6):705-32.

15. Donoso LA, Kim D, Frost A, Callahan A, Hageman G. The role of inflammation in the pathogenesis of age-related macular degeneration. Surv Ophthalmol. 2006; 51(2):137-52.

16. Vingerling JR, Dielemans I, Bots ML, Hofman A, Grobbee DE, de Jong PT. Age-related macular degeneration is associated with atherosclerosis. The Rotterdam Study. Am J Epidemiol. 1995;142(4):404-9.

17. McGeer PL, Rogers J. Anti-inflammatory agents as a therapeutic approach to Alzheimer's disease. Neurology. 1992;42(2):447-9.

18. Johnson LV, Leitner WP, Rivest AJ, Staples MK, Radeke MJ, Anderson DH. The Alzheimer's A beta-peptide is deposited at sites of complement activation in pathologic deposits associated with aging and age-related macular degeneration. Proc Nat Acad Sci U S A. 2002;99(18):11830-5.

19. Burns RP, Feeney-Burns L. Clinico-morphologic correlations of drusen of Bruch's membrane. Trans Am Ophthalmol Soc. 1980;78:206-25.

20. Löffler KU, Lee WR. Basal linear deposit in the human macula. Graefes Arch Clin Exp Ophthalmol. 1986;224(6):493-501.

21. Penfold PL, Killingsworth MC, Sarks SH. Senile macular degeneration: the involvement of immunocompetent cells. Graefes Arch Clin Exp Ophthalmol. 1985:223(2):69-76.

22. van der Schaft TL, Mooy CM, de Bruijn WC, de Jong PT. Early stages of age-related macular degeneration: an immunofluorescence and electron microscopy study. $\mathrm{Br} J$ Ophthalmol. 1993:77(10):657-61.

23. Grindle CFJ, Marshall J. Ageing changes in Bruch's membrane and their functional implications. Trans Ophthalmol Soc U K. 1978;98(1):172-5.

24. Faktorovich EG, Steinberg RH, Yasumura D, Matthes MT, LaVail MM. Photoreceptor degeneration in inherited retinal dystrophy delayed by basic fibroblast growth factor. Nature. 1990;347(6288):83-6

25. LaVail MM, Yasumura D, Matthes MT, Lau-Villacorta C, Unoki K, Sung CH, et al. Protection of mouse photoreceptors by survival factors in retinal degenerations. Invest Ophthalmol Vis Sci. 1998;39(3):592-602.

26. Tao W, Wen R, Goddard MB, Sherman SD, O'Rourke PJ, Stabila PF, et al. Encapsulated cell-based delivery of CNTF reduces photoreceptor degeneration in animal models of retinitis pigmentosa. Invest Ophthalmol Vis Sci. 2002;43(10):3292-8.

27. LaVail MM, Unoki K, Yasumura D, Matthes MT, Yancopoulos GD, Steinberg RH. Multiple growth factors, cytokines, and neurotrophins rescue photoreceptors from the damaging effects of constant light. Proc Natl Acad Sci U S A. 1992;89(23):11249-53.

28. Sieving PA, Caruso RC, Tao W, Coleman HR, Thompson DJ, Fullmer KR, et al. Ciliary neurotrophic factor (CNTF) for human retinal degeneration: Phase I trial of CNTF delivered by encapsulated cell intraocular implants. Proc Natl Acad Sci U S A. 2006;103(10): 3896-901.
29. Zhang K, Hopkins JJ, Heier JS, Birch DG, Halperin LS, Albini TA, et al. Ciliary neurotrophic factor delivered by encapsulated cell intraocular implants for treatment of geographic atrophy in age-related macular degeneration. Proc Natl Acad Sci U S A. 2011;108(15):6241-5.

30. Woldemussie E, Wijono M, Pow D. Localization of alpha 2 receptors in ocular tissues. Vis Neurosci. 2007;24(5):745-56.

31. Burke J, Schwartz M. Preclinical evaluation of brimonidine. Surv Ophthalmol. 1996;41 Suppl 1:S9-18.

32. Lai RK, Chun T, Hasson D, Lee S, Mehrbod F, Wheeler L. Alpha-2 adrenoceptor agonist protects retinal function after acute retinal ischemic injury in the rat. Vis Neurosci. 2002; 19(2):175-85.

33. WoldeMussie E, Ruiz G, Wijono M, Wheeler LA. Neuroprotection of retinal ganglion cells by brimonidine in rats with laser-induced chronic ocular hypertension. Invest Ophthalmol Vis Sci. 2001;42(12):2849-55.

34. Tatton W, Chen D, Chalmers-Redman R, Wheeler L, Nixon R, Tatton N. Hypothesis for a common basis for neuroprotection in glaucoma and Alzheimer's disease: anti-apoptosis by alpha-2-adrenergic receptor activation. Surv Ophthalmol. 2003;48 Suppl 1:S25-37.

35. Donello JE, Padillo EU, Webster ML, Wheeler LA, Gil DW. alpha(2)-Adrenoceptor agonists inhibit vitreal glutamate and aspartate accumulation and preserve retinal function after transient ischemia. J Pharmacol Exp Ther. 2001;296(1):216-23.

36. Collier RJ, Wang Y, Smith SS, Martin E, Ornberg R, Rhoades K, et al. Complement deposition and microglial activation in the outer retina in light-induced retinopathy: inhibition by a 5-HT1A agonist. Invest Ophthalmol Vis Sci. 2011;52(11):8108-16.

37. Yong VW. Differential mechanisms of action of interferon-beta and glatiramer acetate in MS. Neurology. 2002;59(6):802-8.

38. Landa G, Butovsky O, Shoshani J, Schwartz M, Pollack A. Weekly vaccination with Copaxone (glatiramer acetate) as a potential therapy for dry age-related macular degeneration. Curr Eye Res. 2008;33(11):1011-3.

39. Landa G, Rosen RB, Patel A, Lima VC, Tai KW, Perez VR, et al. Qualitative spectral OCT/ SLO analysis of drusen change in dry age-related macular degeneration patients treated with Copaxone. J Ocul Pharmacol Ther. 2011:27(1):77-82.

40. Ding JD, Johnson LV, Herrmann R, Farsiu S, Smith SG, Groelle M, et al. Anti-amyloid therapy protects against retinal pigmented epithelium damage and vision loss in a model of age-related macular degeneration. Proc Natl Acad Sci U S A. 2011;108(28): E279-87.

41. Radu RA, Han Y, Bui TV, Nusinowitz S, Bok D, Lichter J, et al. Reductions in serum vitamin A arrest accumulation of toxic retinal fluorophores: a potential therapy for treatment of lipofuscin-based retinal diseases. Invest Ophthalmol Vis Sci. 2005;46(12): 4393-401.

42. Mata NL, Tsivkovskaia N, Bui TV. Fenretinide reduces the incidence of choroidal neovascularization in patients with geographic atrophy. Invest Ophthalmol Vis Sci. 2011;52:E-abstract 1652

43. Vogel R, Slakter J, McLeod K. A phase II, double-Masked, placebo-controlled, dosecomparison study of the safety and efficacy of fenretinide in the treatment of geographic atrophy in subjects with age-related macular degeneration: Baseline lesion size, characteristics, and preliminary progression data. Invest Ophthalmol Vis Sci. 2009;50: E-abstract 4919.

44. Kubota R, Birch D, David R. Phase 1, dose-escalating study of the safety, tolerability, and pharmacokinetics of ACU-4429 in healthy volunteers. Invest Ophthalmol Vis Sci. 2009;50:E-abstract 5009

45. Hageman GS, Mullins RF, Russell SR, Johnson LV, Anderson DH. Vitronectin is a constituent of ocular drusen and the vitronectin gene is expressed in human retinal pigmented epithelial cells. FASEB J. 1999;13(3):477-84.

46. Mullins RF, Russell SR, Anderson DH, Hageman GS. Drusen associated with aging and age-related macular degeneration contain proteins common to extracellular deposits associated with atherosclerosis, elastosis, amyloidosis, and dense deposit disease. FASEB J. 2000;14(7):835-46

47. Sakaguchi H, Miyagi M, Shadrach KG, Rayborn ME, Crabb JW, Hollyfield JG. Clusterin is present in drusen in age-related macular degeneration. Exp Eye Res. 2002;74(4):547-9.

48. Ishibashi T, Patterson R, Ohnishi Y, Inomata H, Ryan SJ. Formation of drusen in the human eye. Am J Ophthalmol. 1986;101(3):342-53.

49. Feeney-Burns L, Ellersieck MR. Age-related changes in the ultrastructure of Bruch's membrane. Am J Ophthalmol. 1985;100(5):686-97.

50. Killingsworth MC. Age-related components of Bruch's membrane in the human eye. Graefes Arch Clin Exp Ophthalmol. 1987;225(6):406-12.

51. Glybina IV, Kennedy A, Ashton P, Abrams GW, lezzi R. Photoreceptor neuroprotection in RCS rats via low-dose intravitreal sustained-delivery of fluocinolone acetonide. Invest Ophthalmol Vis Sci. 2009;50(10):4847-57.

52. Glybina IV, Kennedy A, Ashton P, Abrams GW, lezzi R. Intravitreous delivery of the corticosteroid fluocinolone acetonide attenuates retinal degeneration in S334ter-4 rats. Invest Ophthalmol Vis Sci. 2010;51(8):4243-52. 